\title{
Application of Value Engineering in Construction Job Sites - A Case Study
}

\author{
Mr. O. Arivazhagan \\ Chief Executive Officer, \\ International Institute of Project Management (IIPM),
} Chennai.

\author{
Mr. V. Guru \\ Assistant Professor \\ Department of Civil Engineering \\ St. Peter's College of Engineering and Technology, \\ Chennai
}

\author{
Dr. P. Partheeban* \\ Professor and Dean (Academic) \\ Department of Civil Engineering \\ St. Peter's College of Engineering and Technology, \\ Chennai \\ Dr. P. Priya Rachel \\ Associate Professor \\ Department of Civil Engineering \\ St. Peter's College of Engineering and Technology, \\ Chennai
}

\begin{abstract}
Value Engineering (VE) is a function-oriented technique that has proven to be an effective management tool for achieving improved design, construction, and cost-effectiveness in various transportation program elements. Value Engineering is one of the most effective techniques known to identify and eliminate unnecessary costs in product design, testing, manufacturing, construction, operations, maintenance, data, procedures and practices. In this study, a questionnaire survey was conducted for Tamilnadu State, India. The questionnaire survey mainly focuses on how effectively value engineering is applied in construction industry and how much the employees are aware of the concept of value engineering and its effectiveness. It is observed that at the initial stage the employees have very good awareness and in due course of project the awareness has gradually reduced. It is concluded that 20 percentage of them are not following specific procedure for implementing value Engineering and remaining 80 percentage following Value Engineering.
\end{abstract}

Keywords-Value Engineering, Construction Projects, Cost Saving, Effeciveness

\section{INTRODUCTION}

Value Engineering (VE) is systematic method to improve the "value" of goods or products and services by using an examination of function. VE (value engineering) was developed at General Electric Corp. during World War II and is widely used in industry and government, particularly in areas such as defense, transportation, construction and healthcare. Value, as defined, is the ratio of function to cost. Value can therefore be increased by either improving the function or reducing the cost. It is a primary theory of value engineering that basic functions be preserved and not be reduced as a consequence of pursuing value improvements.

Value Engineering (VE) within the construction industry is an organized process of reviewing a project with the goal of eliminating unnecessary costs within the project. Dell'Isola [1] defines unnecessary cost within the project as any item that does not provide quality, use, life, appearance or customer features to the project. While the elimination of unnecessary costs through the performance of formal value engineering studies has been proved to be successful in government funded construction projects, the owners of smallscale private construction projects appear reluctant to embrace the value engineering process.

Value analysis is a relatively new system which traces its origins back to the late 1940's. The concept was conceived by Lawrence D. Miles [2], the author of Techniques of Value Analysis and Engineering. It is a system developed for the elimination of unnecessary costs. Value Analysis and Value Engineering is designed to help understanding the unique techniques of value analysis, learning the value analysis job plan, appreciating the major factors in value analysis, and understanding the role of the value specialist in relation to the rest of the organization.

The reasoning behind value engineering is as follows, if marketers expect a product to become practically or stylistically obsolete within a specific length of time, they can design it to only last for that specific lifetime. The products could be built with higher-grade components, but with valueengineering they are not because this would impose an unnecessary cost on the manufacturer, and to a limited extend also an increased cost on the purchaser. Value engineering will reduce these costs. A company will typically use the least expensive components that satisfy the product's lifetime projections.

The goal of a VE study is to achieve design excellence. The VE team is look for the optimum blend of scheduling, performance, constructability, maintainability, environmental awareness, safety, and cost consciousness. The $\mathrm{VE}$ process is not meant to criticize today's designs or insinuate that the regular highway design process is not providing acceptable designs. The designs being prepared today are good designs, they can be built, and they will function as intended. The following are the objectives of the study:

- To apply the value engineering methodology in the construction job sites / industry for achieving cost 
effectiveness, reduction in construction time and improve the safety.

- To identify the areas where the value engineering can be applied in order to improve the quality of construction.

- To Identify the importance and benefits of application of value engineering techniques

\section{LITERATURE REVIEW}

Value Analysis is an important topic to be discussed especially in the field of engineering. Many literatures has been discussed which highlights the importance of value engineering in all braches. The process of value engineering was developed during World War II by Lawrence Miles [3], an electrical engineer for General Electric Company, in response to material shortages created during war. The war production effort required products to be manufactured but the material shortages forced the specification of different materials. Lawrence Miles discovered that many of the products being produced with the substituted materials performed the equivalent function of the original product and at a reduced cost. The literature related to application of value engineering is discussed here.

Apurva [4] studied on Value Engineering in Construction Industry. This paper presents the basic fundamental of Value Engineering and its different phases that can be implemented in any construction industry in general to optimize its value. The material is chosen such that the cost is reduced without affecting the value of the product and its design.

A study by Amruta Chougule et.al., [5] on Application of Value Engineering Technique to A Residential Building -Case Study. They have applied values engineering in a residential building. The application of Pareto Law 20/80 states that around $20 \%$ of the functions constitute around $80 \%$ of the cost. These functions $(20 \%)$ are the subject of value engineering. Likewise they observed that the first 6 items (out of 16) forms $61.53 \%$ of the total cost. As a conclusion, the area of value engineering analysis and study will be controlled by the first six functions. Further, they told that we can do analysis of these functions and suggest alternatives and calculate cost model after application of value engineering technique.

Another study on Application of Value Engineering in Road Construction Project by Sayali Dhayalkar and Hemanshu Ahire [6] have discussed the concept of Value Engineering and the effective implementation on road construction project. Their application of Pareto Law 20/80 states that around $20 \%$ of the functions constitute around $80 \%$ of the cost. These functions $(20 \%)$ are the subject of value engineering. Likewise it was observed that the first 3 items (out of 13) forms $73.3 \%$ of the total cost. As a conclusion, the area of value engineering analysis and study will be controlled by the first three functions.

Rane and Attarde [7] studied on Application of Value Engineering in Commercial Building Projects. Their methodology is composed of three main stages. The first stage is the Pre-Study of the Value Engineering. The second stage is the Value Study which is the core of Value Engineering study and it is composed of five phases, the Information phase, Function Analysis Phase, Creative Phase, Evaluation Phase and the Presentation phase. The third stage is the Post Study. The objective during post-study activities is to assure the implementation of the approved value study change recommendations. In this study, the principles of Value Engineering and the application in construction projects is explained, and by taking case study on commercial building as the sample project, practices of Value Engineering in this project are described. They concluded that the area of value engineering analysis and study will be controlled by the functions.

Li Ning [8] carried out a study on Cost Control Application Research of Value Engineering in the Design Phase of Construction Project. In his paper, based on this perspective, applies value engineering to the project design to meet the requirements of continuously put forward the development of the real estate design and makes the value engineering meet the requirements of developing value engineering theory at the same time.

Stephen Mansfield and Philip D. Udo-Inyang, [9], Application of Value Engineering within the Construction Industry The current perception and application of value engineering was established through a survey questionnaire sent to various members of the construction industry which asked detailed questions on the participants' knowledge and experience with value engineering. Results were analyzed which indicated that the majority of the survey participants do not participate in value engineering studies and do not understand the true concept of value engineering even though eighty-four percent of the participants stated positively that value engineering is performed on the projects in which they are members of the project team.

\section{RESEARCH METHODOLOGY}

It has been understood from the literature review that selecting the ways of analyzing VE plays an important role. The value engineering is a set of procedure or an immense performance related application to it in the construction job site. Further, the project development and success mainly depends on the methodology that is selected to attain the objective. Clearly identify the problem(s) to be solved, and gather information on the background, functions and requirements of the project. Clearly identify the problem(s) to be solved, and gather information on the background, functions and requirements of the project. Understanding the basic concept of value engineering is the important term in correlating the process of value engineering methodology. The orientation also deals with the process of applying in industries and analyzing it in better predominant manner,

In this study, a set of questions were put together as a full format and it has been correlated into a questionnaires. The questions are only based on the awareness that every construction industries posses on value engineering and how $\mathrm{VE}$ is implemented in their industry, how team members are selected for VE, Benefits of implementing VE, training or workshop in VE, etc. Steps involved in the delegation of authority involving in the industry. After preparation of 
questionnaire a pilot study was conducted to find out any problem in the prepared questionnaire

The prepared questionnaires are submitted for a detailed survey in a construction job site to a three levels of workers involved in it. Workers include bondsman, engineer and supervisor of the construction industries. The questionnaire survey was conducted for a whole entire Tamilnadu state. For the study the questionnaires were sent to several construction industries in 13 districts in person and by post. Fifty questionnaires were used for conducting survey and got $54 \%$ response. The collected questionnaires are analysed based on workers level and then sorted out on the bases of large scale construction and small scaled one. Questionnaire can be viewed and analyzed for results at any time during the collection process in the Analyze section of the survey. This section mentioned about summary view of individual data ; browse individual responses; create and export dynamic charts; use filter, compare, and show rules to analyze specific data views and segments; view and categorize open-ended responses, and easily download the results in multiple formats. Questionnaire collected are mainly analyzed with their individual response to the concept of Value Engineering.

\section{RESULTS AND DISCUSSION}

Fig. 1 shows the rate of responses to the sent questionnaires. The questionnaires also were meant to cover the main players in the industry, as $40 \%$ of the responses received were from contractors, $40 \%$ from consultants and $20 \%$ from owner's representatives. The respondents who had 20 years of experience or more were $53 \%$ of the total responses, while those who had experience between 10 to 20 years were $47 \%$. It is observed that $60 \%$ of the experts working in Chennai and the remaining $40 \%$ were working in other parts of Tamil Nadu. In the part asking "who decides which construction method to be used?" $73 \%$ of the respondents chose more than one person for this task, while $27 \%$ named one person to be responsible for it. These results are presented in Fig. 2. Project Managers about $53 \%$ of them are designer should be one of the decision makers. While $47 \%$ found that it should be the consultant, $33 \%$ considered the cost estimator and the site manager and only $20 \%$ mentioned the client.

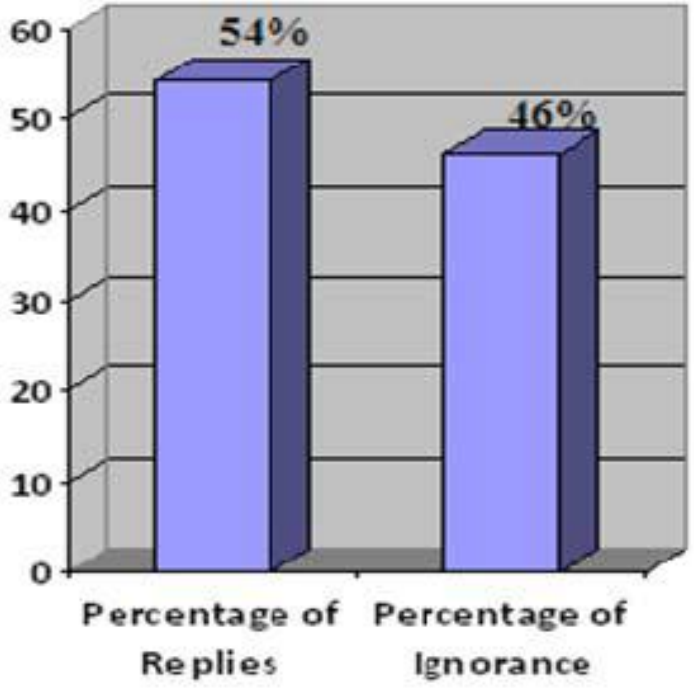

Fig. 1 Percentage of Responses Received

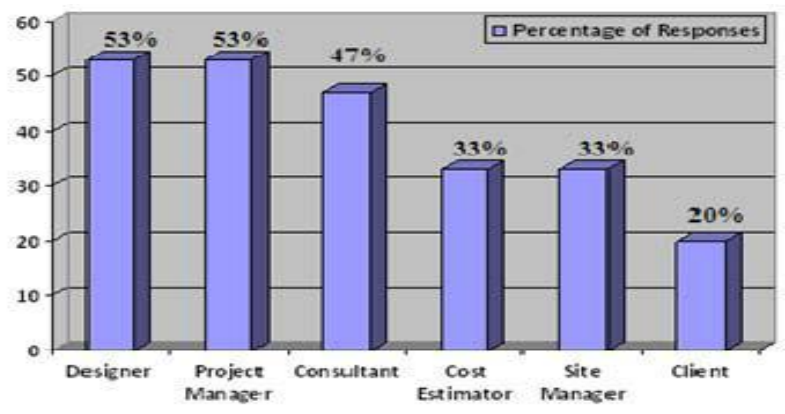

Fig. 2 Percentage of Decision Makers in the Construction Method

Then $80 \%$ stated there is a specific procedure for selecting the most appropriate construction method. In the other hand $20 \%$ denied that there is a specific procedure for the selecting process. The $80 \%$ using a specific procedure mentioned some of the factors, such as nature of crossing, cost, equipment, workmanship skills, duration of the project, bridge's different physical characteristics, soil condition, the used materials, surrounding area nature and cranes capacity.

Focusing on the field of Value Engineering, $83 \%$ of the respondents reported that $\mathrm{VE}$ technique is being implemented in order to select the most appropriate construction method and $17 \%$ stated that they don't use it. All the $83 \%$ assured that the VE technique is being applied before constructing the project. After that the respondents were asked about the range of savings in the project's total cost that could be achieved by implementing the Value Engineering Technique. $60 \%$ of them couldn't decide the range as it varies from a project to another, While $40 \%$ estimated that the savings are from 20 to $25 \%$. Only $20 \%$ of the respondents applying Value Engineering technique have a special team responsible for this task. The other $80 \%$ considered that it is the responsibility of the designer or the consultant and a few mentioned the contractor. 


\section{CONCLUSIONS}

Twenty percentages of the respondents didn't have a specific procedure for the selection process and even the respondents who have one couldn't specify this procedure. This fact reflects the randomness which may occur in the construction industry without good planning. The selection process is highly affected by the physical characteristics of bridges, surrounding environment (surrounding area nature, soil subsurface conditions, nature of building and land topography) and to a less extent by construction method characteristics (cranes capacity and manoeuvring, accessibility and the used material). $25 \%$ of the respondents reported that they implement the Value Engineering technique in the process of selecting the most appropriate construction method, It means that the awareness of applying Value Engineering technique is very less. All the respondents agreed that the Value Engineering technique should be applied in the very beginning of the project through the preliminary studies and in the beginning of the design phase.

The respondents assured that there will be a significant amount of savings due to applying the Value Engineering in the range of $20 \%$ to $25 \%$ of the project total cost. $53 \%$ of the respondents of the one who apply Value Engineering were aware that the designer and the project manager should select the bridge. Construction method, while only $33 \%$ mentioned the cost estimator which is alarming. Most of the respondents admitted that they don't perform an organized Value Engineering job plan as supposed. It is obvious that the Value Engineering technique still not being applied $\mathrm{p}$ as $100 \%$ of the respondents who claimed applying the VE technique stated that they mainly depend on their own previous experience in choosing the most appropriate construction method, which is very confusing.

\section{ACKNOWLEDGMENT}

The authors acknowledge International Institute of Project Management for sponsoring this research project. The author's also gratefully acknowledge the work done by Mr.Anirudhan. M, Mr.Aravind Raj Kumar.B, Mr.Balaji. G and Mr.Mohan Raj. S for collecting data for this research work.

\section{REFERENCES}

[1] Dell'Isola, Alphonse J. (1974). Value Engineering in the Construction Industry. Construction Publishing Company, New York

[2] Miles, Lawrence D. (1961). Techniques of Value Analysis and Engineering. McGraw-Hill, New York

[3] Thiry Michel (1997). Value Management Practice. Project Management Institute, Sylva, NC

[4] Apurva J Chavan, (2013), Value Engineering In Construction Industry, International Journal of Application or Innovation in Engineering \& Management, Volume 2, Issue 12, pp. 18-26.

[5] Amruta Chougule et.al., (2014), Application of Value Engineering Technique to A Residential Building - Case Study, International Journal of Innovative Research in Advanced Engineering (IJIRAE), Volume 1 Issue 12, pp. 115-118.

[6] Sayali Dhayalkar and Hemanshu Ahire, (2016), Application of Value Engineering in Road Construction Project, Imperial Journal of Interdisciplinary Research (IJIR) Vol-2, Issue-11, PP.101-104.

[7] Nitin L. Rane and P.M. Attarde, (2016), Application of Value Engineering in Commercial Building Projects, International Journal of Latest Trend in Engineering and Technology, Vol. 6 Issue 3, pp. 286291.

[8] Li Ning, (2015), Cost Control Application Research of Value Engineering in the Design Phase of Construction Project, International Conference on Economics, Social Science, Arts, Education and Management Engineering, pp. 390-396.

[9] Stephen Mansfield and Philip D. Udo-Inyang, (2006), Application of Value Engineering within the Construction Industry, SC Proceedings of the 42nd Annual Conference Colorado State University Fort Collins, Colorado. 